\title{
Miliary Hepatic Metastases from Neuroendocrine Carcinoma
}

\author{
Nicola Fazio Giovanni Di Meglio \\ European Institute of Oncology, Milan, Italy
}

A 57-year-old man with a bronchial carcinoid, metastatic from 1999, underwent cholecystectomy in 2004, due to lithiasis, probably caused by long-lasting therapy with somatostatin analogs.

Liver metastases had been known since 2002 on the basis of a previous computed tomography (CT) and somatostatin receptor scintigraphy (SRS). Intraoperatively a miliariform hepatic dissemination was evident (fig. 1), and was much more extended than previously seen on CT and SRS.

The liver is often involved in the metastatic spread of neuroendocrine carcinomas (NECs). The morphological heterogeneity of these neoplasms takes into account the varying accuracy of instrumental examinations. Magnetic resonance imaging was superior to CT and SRS in the detection of hepatic metastases from NECs. However, none of these examinations was able to detect the miliariform dissemination in the liver, and therefore the tumor burden was underestimated. This could be of crucial importance for clinicians when deciding on the therapeutic strategy, i.e. the indication for resection.

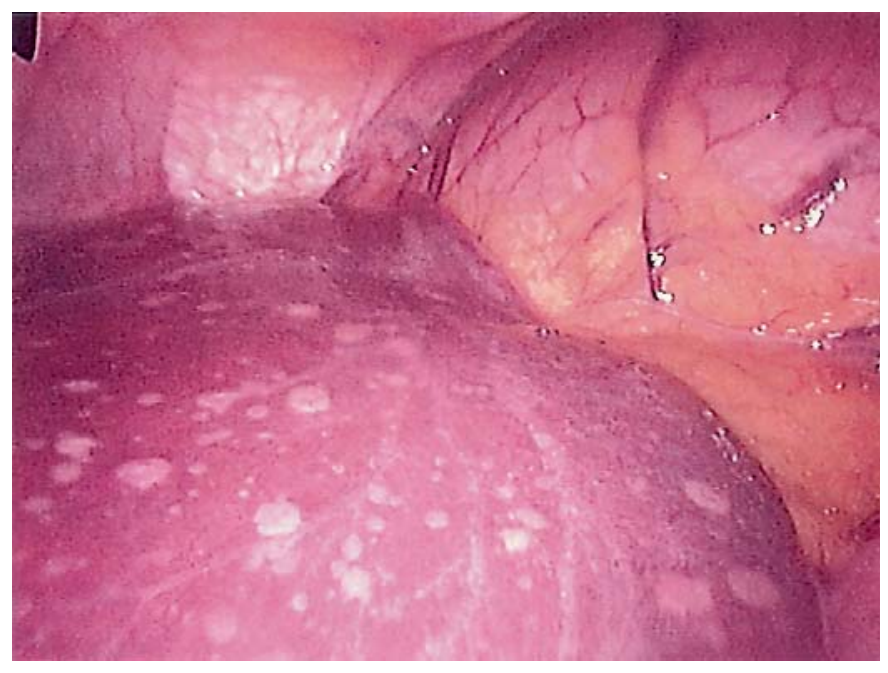

Fig. 1. Miliary hepatic metastases from a neuroendocrine carci-

\section{KARGER}

Fax +41613061234 E-Mail karger@karger.ch www.karger.com noma.

Filippo de Brand 